\title{
Strategic Plan for Hanford Site Information Management
}

Date Published

September 1994

RECEIVED

MAR 121996

OSTI

Prepared for the U.S. Department of Energy

Office of Environmental Restoration and

Waste Management

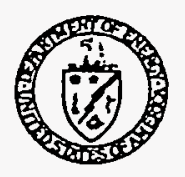

United States

Department of Energy

P.O. Box 550

Richland, Washington 99352

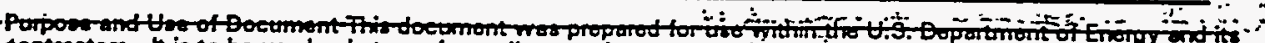

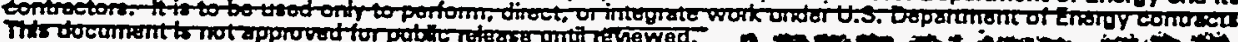

$\operatorname{tin} \beta \operatorname{lin}_{16} / 96$

APPROVED FOR

PUBLIC RELEASE

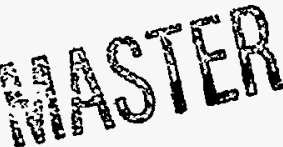

DISTAIBUTION OF THIS DOCJUIENT IS UNLIMITED 
LEGAL DISCLAIMER

This report was prepared as an account of work sponsored by an agency of the United States Government. Neither the United States Government nor any agency thereof, nor any of their employees, nor any of their contractors, subcontractors or their employees, makes any warranty, express or implied, or assumes any legal liability or responsibility for the accuracy, completeness, or any third party's use or the results of such use of any information, apparatus, product, or process disclosed, or represents that its use would not infringe privately owned rights. Reference herein to any specific commercial product, process, or service by trade name, trademark, manufacturer, or otherwise, does not necessarily constitute or imply its endorsement, recommendation, or favoring by the United States Government or any agency thereof or its contractors or subcontractors. The views and opinions of authors expressed herein do not necessarily state or reflect those of the United States Government or any agency thereof.

This report has been reproduced from the best available copy. Available in paper copy and microfiche.

Available to the U.S. Department of Energy and its contractors from

U.S. Department of Energy

Office of Scientific and Technical Information (OSTI)

P.O. Box 62

Oak Ridge, TN 37831

(615) $576-8401$

Available to the public from the U.S. Department of Commerce National Technical Information Service (NTIS)

5285 Port Royal Road

Springfield, VA 22161

(703) $487-4650$

Printed in the United Stateg of America

DISCLM-1.CHP (8-95) 


\title{
STRATEGIC PLAN FOR HANFORD SITE INFORMATION MANAGEMENT
}

\begin{abstract}
MISSION
The mission for Hanford Site information management is to create a working environment that delivers the right data and information of known quality in a usable form and at an acceptable cost to the people who need it, where they need it, and when they need it.
\end{abstract}

\section{VISION}

The vision for Hanford Site information management is to demonstrate organizational and technical excellence in meeting customer needs by:

- Supporting information analysis and decisionmaking

- Enabling data integration and comparison from multiple sources

- Providing quality-assessed data and information

- Developing capabilities that allow ease of information use and access.

\section{ISSUES}

- Recognition of data and information as a Site resource is limited.

- Integration of information management into the business process is needed.

- Site wide leadership, policies, standards, defined responsibilities, and funding support is needed.

- Increased communication and teamwork is needed.

- Customer needs are not clearly defined.

- Information management priorities for infrastructure and system improvements are not driven by customer needs.

- Increased data access and sharing is needed.

- The Hanford Site information architecture is not adequately defined or integrated.

- Efficient and flexible processes for information collection, retrieval, processing, and delivery are needed.

- Data and information quality is not well defined or documented.

- Hardware/software needs are not adequately anticipated and coordinated.

- Required technologies need to be evaluated and acquired.

\section{STRATEGIES}

- Structure and maintain a Sitewide management and control process for information management.

- Sustain Sitewide leadership to ensure effective information management.

- Enhance and refine the data collection process.

- Develop an information access and delivery mechanism.

- Establish information analysis processes that support customer needs.

- Develop an effective and efficient Hanford Site information architecture. 


\section{CONTENTS}

1.0 INTRODUCTION $\ldots \ldots \ldots \ldots \ldots \ldots \ldots \ldots \ldots \ldots \ldots \ldots \ldots \ldots \ldots \ldots$

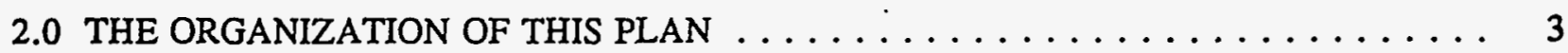

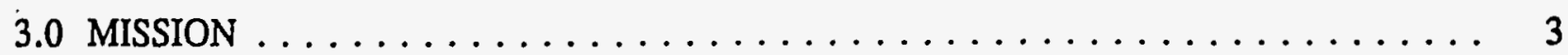

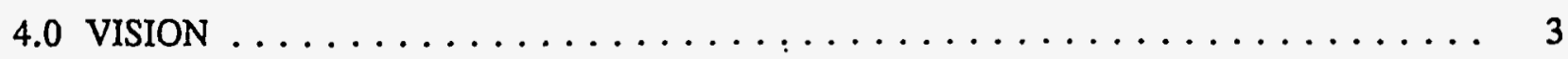

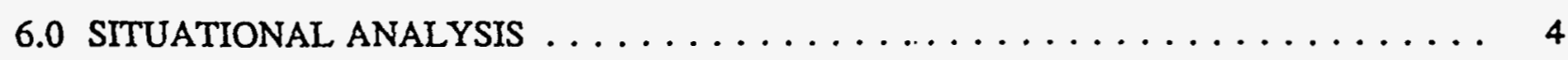

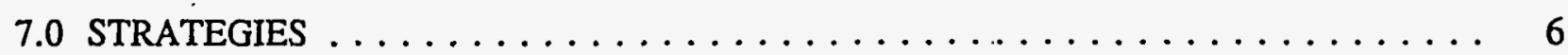

Strategy 1: Structure and maintain a Sitewide management and control process for information management $\ldots \ldots \ldots \ldots \ldots \ldots$. . . . . . . . 9

Strategy 2: Sustain Sitewide leadership to ensure effective information management $\ldots \ldots$. 10

Strategy 3: Enhance and refine the data collection process . . . . . . . . . . . . 11

Strategy 4: Develop an information access and delivery mechanism . . . . . . . . 12

Strategy 5: Establish information analysis processes that support customer needs . . . . . 13

Strategy 6: Develop an effective and efficient Hanford Site information architecture . . . . 14

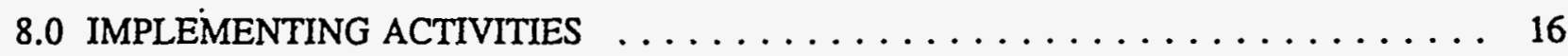

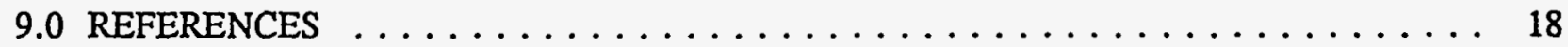

APPENDICES

A HANFORD SITE DATA AND INFORMATION MANAGEMENT POLICY $\ldots \ldots \ldots$. . A A-1

B THE INFORMATION ARCHITECTURE $\ldots \ldots \ldots \ldots \ldots \ldots \ldots \ldots \ldots \ldots$

C THE PLANNING PROCESS $\ldots \ldots \ldots \ldots \ldots \ldots \ldots \ldots \ldots \ldots \ldots \ldots$

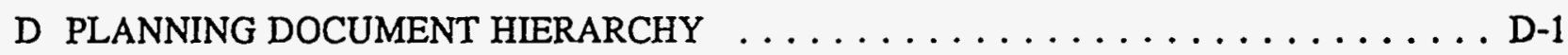




\section{LIST OF FIGURES}

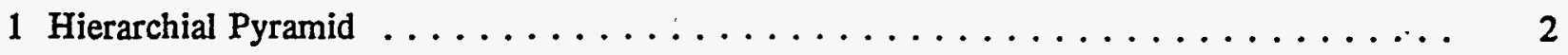

2 Strategy Relationships $\ldots \ldots \ldots \ldots \ldots \ldots \ldots \ldots \ldots \ldots \ldots$

3 Issues Mapped to Strategies Matrix . . . . . . . . . . . . . . . 15

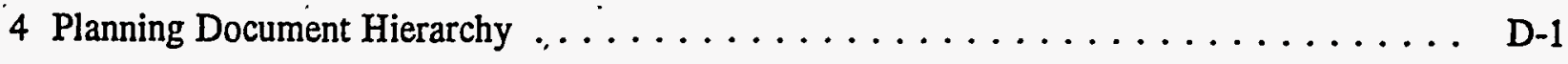




\section{LIST OF TERMS}

$\begin{array}{ll}\text { CASE } & \text { Computer Assisted Systems Engineering } \\ \text { CIO } & \text { Chief Information Officer } \\ \text { DMP } & \text { Data Management Plans } \\ \text { DOE } & \text { U.S. Department of Energy } \\ \text { EM } & \text { Environmental Management } \\ \text { ER } & \text { Environmental Restoration } \\ \text { HSP } & \text { Hanford Strategic Plan } \\ \text { RL } & \text { U.S. Department of Energy, Richland Operations Office } \\ \text { WHC } & \text { Westinghouse Hanford Company }\end{array}$




\section{STRATEGIC PLAN FOR HANFORD SITE INFORMATION MANAGEMENT}

\subsection{INTRODUCTION}

The Hanford Site missions are to clean up the Site, to provide scientific knowledge and technology to meet global needs, and to partner in the economic diversification of the region. To achieve these longterm missions and increase confidence in the quality of the Site's decisionmaking process, a dramatically different information management culture is required, consistent with U.S. Department of Energy (DOE) mandates on increased safety, productivity, and openness at its sites. This plan presents a vision and six strategies that will move the Site toward an information management culture that will support the Site missions and address the mandates of DOE.

The past culture at the Site was justifiably inwardly focused with data flow limited to organizations having a "need to know." Data were frequently contained in file cabinets, paper reports, central repositories, and in the minds of the original data collectors. National security requirements limited data dissemination. Data sharing was difficult, if not impossible. Currently, much of the site data and information are scattered across contractors and managed under multiple organizations on numerous computer systems in incompatible, nonstandard formats. This situation makes it difficult for the Site to access its own information, and precludes timely access for offsite customers who have a requirement for the information.

Information is the key infrastructure element in decisionmaking. Site management and staff make decision that have tremendous impacts on worker safety, environmental cleanup, science for global problems and economic diversification. The free flow of information during decisionmaking and review processes enables open and active communication and results in decisions that are traceable and defensible.

Lack of adequate information management affects staff productivity. Although few at the Site think of themselves as information managers, information management is a "second business" for many staff since much of their time is spent performing information management activities to support their primary work. Because of a lack of adequate information management, these staff members are often unable to meet the Site's current information management needs. During the last half of this decade, the Site's cleanup, technology development, and scientific research activities will cause a massive expansion of our onsite data and there will be increasing pressure to effectively manage more information as characterization and waste remediation activities mature. This will be accompanied by the need to store, access, visualize, and analyze these data to make well-supported technical and business decisions. How will staff meet the growing needs of information management? Information technology, such as computers, database systems, geographic information systems, file management systems, and optical disk storage, coupled with effective business processes, can enable the staff to become more effective information customers who are able to quickly sift through the data to reach the needed pieces of information . 


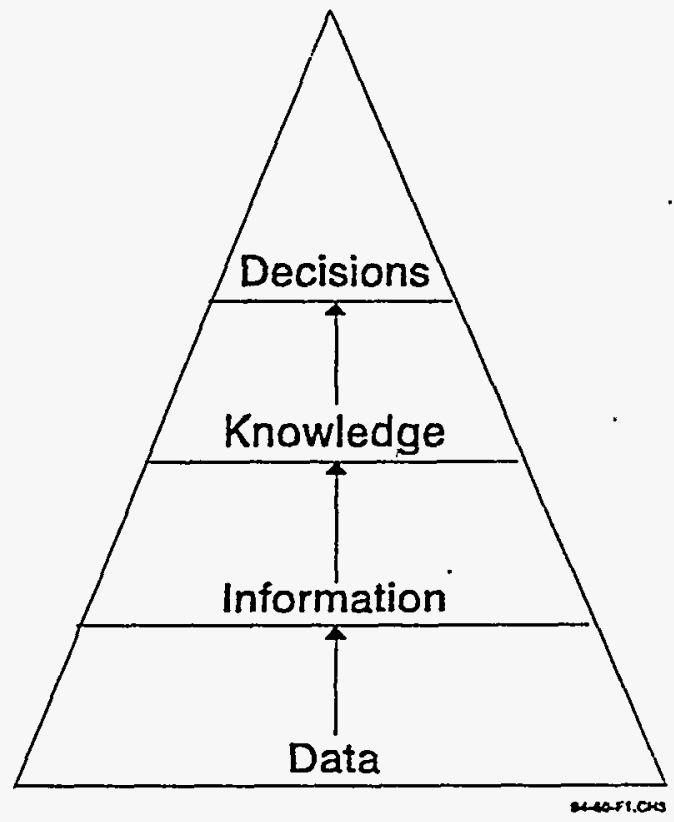

Figure 1.

The pyramid in Figure 1 illustrates the hierarchial relationship between data, information, knowledge, and decisions. The process begins with the collection of raw data (e.g., facts associated with some type of measurement or observation). The results are combined and analyzed to provide useful information. That information is combined with other information sources to provide the knowledge. Conclusions drawn from this entire process give rise to well-informed decisions. In this plan, no attempt is made to differentiate between data and information since the distinction is not relevant to the discussion that follows. What is information to one customer may be data to another.

Information is defined for this plan as all key administrative and technical data used to carry out the Hanford Site missions. This information is found in databases, documents, maps, images, videotapes, and other media. If any one of these forms of information meets established records management criteria, it can be a record, regardless of its physical form or characteristics. Effective information management is more than the compilation of massive amounts of electronic and non-electronic information; it involves integrating information management into business processes that identify requirements, compliment and enable priorities and practices, and enable communication. Effective information management can enable work to be done better, faster, and with greater cost efficiency. Inadequate information management can obstruct work completion, drain resources better spent elsewhere, and prevent value-added qualities. This strategic plan focuses on how to make information management an enabler rather than a barrier.

Effective information management must become a Site priority, with associated planning, coordination, staffing, and technology resources. Site information resources will serve a key role in improving the technical quality of work, increasing stakeholder confidence in the management of Site programs, and diversifying the local economy. Easy access to the Site's unique knowledge base and technical expertise will help facilitate these activities. A Sitewide, multiprogram approach is needed that is streamlined, standardized, networked, and focused both inward on the Site community and outward on critical external stakeholders. This new information management culture will enable data and information to be readily transmitted, shared, and analyzed between organizations. Information management resources need to conform to Sitewide policies, standards, processes, procedures, and guidelines. Within that context, programs must retain the freedom to shape and control the specific information management approach and technology required to meet unique program decisionmaking needs. However, providing standardized, easy access to information is not the same as making the data usable. Customers often need context, subject area knowledge, training, and support before they can use complex technical or administrative information. Customers must be aware of the quality of the data so they can assess whether the quality makes the data appropriate for the intended use.

Information technology continuously advances and major new developments are being announced frequently. These advances will allow the Site to use cost-and time-saving capabilities, such as electronic document management and multimedia, that were unavailable only a few years ago. These newer 
technologies need to be integrated with the Site's current capabilities so that the Site's knowledge base is preserved and available for use. This plan proposes the establishment of a Hanford Site "information architecture" to integrate these information technologies, help prevent the obsolescence of the Site's information technology investments, and aids in the delivery of information management capabilities to the customers. The definition of an information architecture is described in more detail in Appendix B. This plan does not propose to integrate all information and information systems but encourages the sharing and use of information (with special features to support privacy and business sensitivity requirements). A prioritization process is needed to determine what should be integrated based on the needs of the customer.

\subsection{THE ORGANIZATION OF THIS PLAN}

This plan provides a high-level framework and direction for Hanford Site information management. Background information describing the process used to develop this plan is in Appendix C. As with most strategic plans, this plan should be revisited at least annually to assess progress in implementing the plan and align the plan to reflect the Site's strategic directions and current information management state. The mission and the vision are quite broad and describe the future state that this plan is attempting to achieve. The goals, which evolved from the mission and vision, are also quite broad. The situational analysis describes where the Site currently is relative to information management and outlines the obstacles the Site must overcome to reach the plan's vision. The strategies and actions are based on a five-year outlook. Working within the strategic framework created by this plan, some critical activities can and should be implemented immediately. Other activities can be phased in over the next five years.

\subsection{MISSION}

The Hanford Site information management mission is to create a working environment that delivers the right data and information of known quality in a usable form and at an acceptable cost to the people who need it, where they need it, and when they need it. This environment will enable the data and information to be used and managed as valuable resources, supporting technical analyses, and enabling informed decisionmaking.

\subsection{VISION}

The vision for Hanford Site information management is to demonstrate organizational and technical excellence in meeting customer needs by: supporting information analysis and decisionmaking, enabling data integration and comparison from multiple sources, providing qualityassessed data and information, and developing capabilities that allow ease of information use and access. Achieving this vision will assist the Hanford Site in transforming its previous culture of information restriction to a new culture of information access where the Hanford Site becomes an internationally recognized source of information critical to solving complex environmental and technical problems. 


\subsection{GOALS}

The following goals were developed to accomplish the Hanford Site information management vision:

1. Provide an information management environment that enables customers to work more effectively and efficiently.

2. Make relevant and appropriate data and information accessible for data analysis and decisionmaking.

3. Integrate information to meet the needs of customers and to achieve the most efficient use of data.

4. Establish leadership for integration of Sitewide information management that encourages teaming and improved communication.

5. Use information technology to provide easy access to electronically stored information.

6. Implement practices for working with heterogeneous, distributed computer systems that will enable the Hanford Site and others to deal with diverse systems.

7. Sustain a high-quality, effective, and accessible customer-training, documentation and support program to ensure that information customers have the tools to accomplish their tasks.

8. Enable data sharing, comparability, and traceability.

9. Reduce cost and schedule impacts of data redundancy, gaps, misunderstandings, and misuse.

10. Enable "one-stop" access to locate Hanford Site information.

\subsection{SITUATIONAL ANALYSIS}

The vision of this strategic plan was compared to the current information management environment at the Hanford Site through an examination of trends, assumptions, strengths, weaknesses, opportunities, and obstacles. The resulting situational analysis identified the issues that require resolution before the vision and goals can be accomplished. The material covered in this section is a summary of the major points covered by that analysis.

Hanford Site management has a growing awareness of the impact information management has to the success of the Site missions and understands that effective and efficient information management is vital to the containment of cost, quality of work, and decisionmaking. Management is committed to working with stakeholders, including the regulators, to provide appropriate, high-quality information in a timely manner. Our technical staff are committed to providing high quality analyses of critical Site data to support decisionmaking. Staff expertise is available a for developing a Sitewide integrated information management process. Some information management processes are in place while others need to be established. Sitewide processes are needed to improve information management effectiveness and information availability. 
However, the need for the high degree of information management coordination and technology required to achieve the Hanford Site missions and meet customer needs for documentation and information generally is not recognized as a high priority. The administrative and technical information environment is highly complex, with extensive efforts often required to develop, store, analyze, and access data and information. Organizational issues and short-term competing priorities complicate the effort. Today, information often is not linked to key decisionmaking, nor is the process of using data and information to make decisions well understood. While the Site has valuable historical data and is collecting new data, onsite customers cannot always find or access the information they need to perform their assigned tasks. Offsite customers find it very difficult to access Hanford Site information.

Significant costs are now incurred to manage information at the Hanford Site, but the funds are not always effectively spent because of redundant systems, cumbersome procedures, overlapping organizational responsibilities, and the lack of knowing what information is really important to Hanford Site decisionmaking. Many costs are not visible making the true cost of the Site's present handling of information very difficult to quantify. The current funding approach is fragmented and hinders coordination of Sitewide efforts to integrate and develop cost-effective information infrastructure. Many existing information management systems were not designed with outside workgroups or multiorganizational uses in mind, are not easily accessible, are not scalable, and do not conform to new Site data standards. There is no process in place for setting Sitewide information management priorities. Redundancies, incongruities, and gaps among the databases and applications that support the Site missions are common. Although there is a trend toward increased sharing and integration of data, ownership and security issues still account for some resistance to an open information management culture. The existing Hanford Site information network has improved the ability to communicate and share data, but it has significant limitations that are barriers to effective data accessibility.

\section{ISSUES}

- Recognition of data and information as a Site resource is limited.

- Integration of information management into the business process is needed.

- Site wide leadership, policies, standards, defined responsibilities, and funding support is needed.

- Increased communication and teamwork is needed.

- Customer needs are not clearly defined.

- Information management priorities for infrastructure and system improvements are not driven by customer needs.

- Increased data access and sharing is needed.

- The Hanford Site information architecture is not adequately defined or integrated.

- Efficient and flexible processes for information collection, retrieval, processing, and delivery are needed.

- Data and information quality is not well defined or documented.

- Hardware/software needs are not adequately anticipated and coordinated.

- Required technologies need to be evaluated and acquired.

The issues above identified in the situational analysis led to the identification of specific areas for improvement:

- Business Perspective: Data and information are valuable Hanford Site resources and must be managed from a business perspective to support the Site missions. Integration of information management into the business process is needed to maintain a balance between the needs of the 
Hanford Site with those of individual programs or functions. Leadership is required to provide sitewide policies and standards, define responsibilities, and identify methods of providing appropriate funding support. Increased communication and teamwork is essential-for coordination of information management planning and implementation across the Hanford Site's many programs and contractor organizations.

- Customer Focus: Increased emphasis must be placed on the definition and satisfaction of both internal and external customer needs. Customer needs for data access, analysis, and reporting must drive the information management priorities for infrastructure and system improvements. Facilitating, prototyping, and other cooperative efforts between the customers and implementers of information technology can be used to ensure a thorough articulation of requirements. Increased data access and sharing by information generators, customers, and contractors can enable work to be done more effectively.

- Integrated Information Architecture: A Hanford Site information architecture is needed that integrates business processes, data, technology, and applications. An architecture provides a framework to guide migration and development of information systems and associated computer-. based infrastructure. A Hanford Site architecture is needed that focuses on the ability to access data anywhere and the ability to run critical applications when and where customers need them. The architecture must be flexible and adaptive to change in mission, budget, or technological developments.

- Data Collection, Retrieval, Processing, and Delivery: Establishment and maintenance of efficient and flexible processes with appropriate safeguards for information collection, retrieval, processing, and delivery in a customer-friendly fashion are key to the support of the Hanford Site missions. A wide variety of data and records must be supported.

- Data Quality: Data and information quality is critical to data use and must be considered throughout the collection, processing, retrieval, and delivery process. Data quality must be assessed and serve as a guide to the application and limitations of the data use. The data can then serve the original purpose and also be adaptable to new uses.

- Technology Focus: State-of-the-art information technology allows continuing development of new capabilities that can be applied to meet evolving customer requirements and to support Hanford Site missions and goals. Hardware and software needs must be anticipated and the technologies evaluated and acquired to provide current and future capabilities in a cost-effective and efficient manner.

\subsection{STRATEGIES}

The six strategies outline general actions that address the issues and provide the vehicle for change to accomplish the information management mission. The strategies are consistent with other planning documents as described in Appendix $D$. They include actions that enable strategies described in the Hanford Strategic Plan. They bridge the gap between the current environment and the future as stated in the vision. The strategies lead the Site to an environment that observes the principles stated in the "Hanford Site Data and Information Policy" (Appendix A). 
The relationship between the strategies is shown in Figure 2. The first two management strategies deal with leadership and management control. They must be achieved to enable the remaining strategies to be carried out effectively. They provide direction and focus for the operational activities of data collection, access, and processing described in Strategies 3 through 5. The information architecture in Strategy 6 provides the framework to implement the operational activities. The success criteria will be used to evaluate progress for each strategy when the plan is reviewed (at least annually). Implementation plans will be written to translate the high-level direction provided in these six strategies into detailed actions. The matrix, following the strategies, maps the issues to the resolving strategies. 


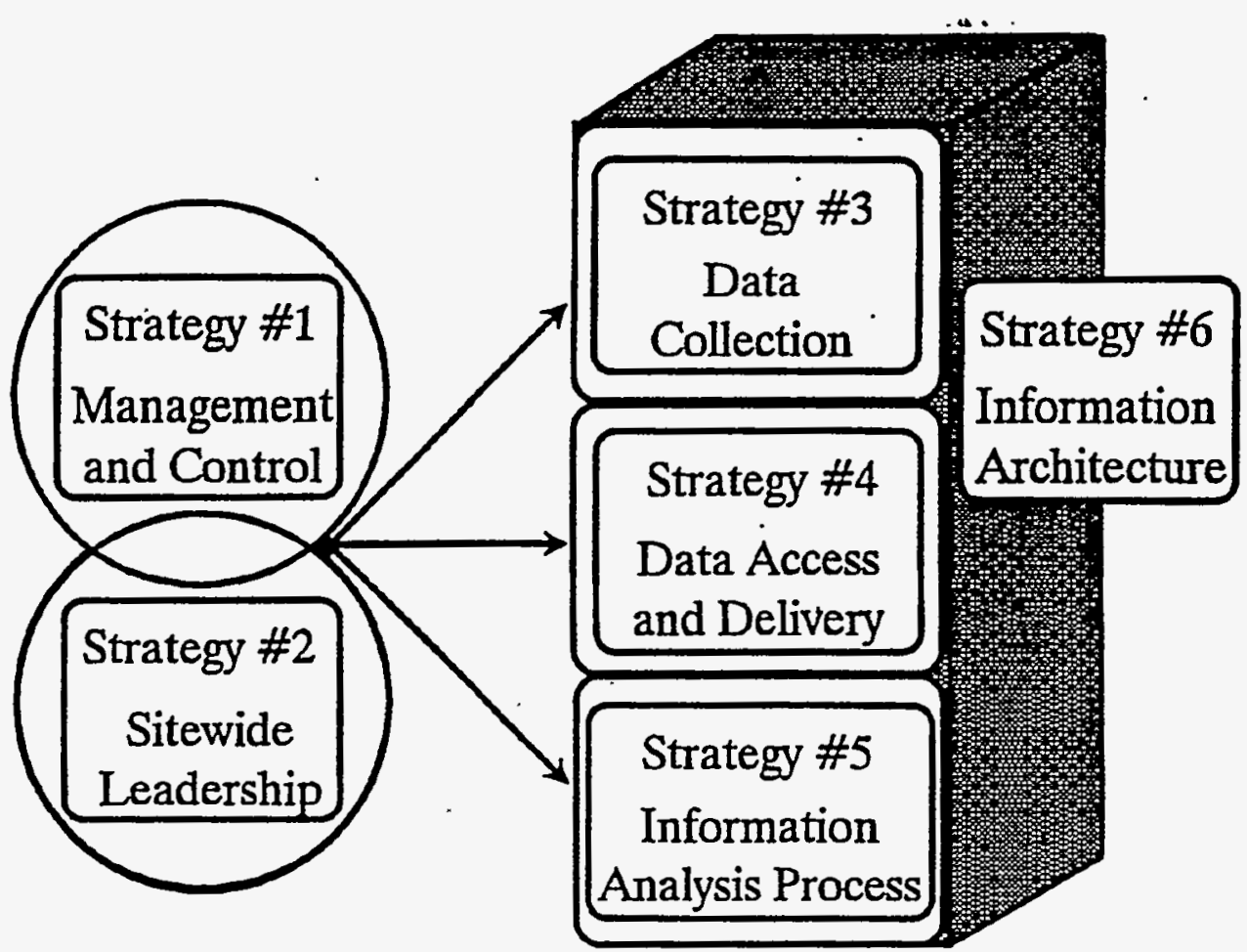

Figure 2. Strategy Relationships. 
Strategy 1 structure and maintain a Sitewide management and control process for information management.

Strategy Statement: Strong, involved, supportive management is essential to achieve Sitewide integrated information management as well as to achieve maximum return on present and future investments of funding and resources. The intent of this strategy is to enable and maintain effective day-to-day operations, guidance, and compliance for information management. This strategy focuses on establishing a management structure and information management practices (e.g., policies, standards, processes, procedures, guidelines), and includes the following:

- Develop a Sitewide information management business plan, congruent with the Site Management System, that identifies and analyzes the major business processes and required information management resources and expenditures, and implements a financial plan for funding an information infrastructure and architecture.

- Define, communicate, manage, and enforce Sitewide information standards.

- Define Hanford Site information management roles and responsibilities.

- Establish clear lines of management responsibility for information management.

- Identify a Site Chief Information Officer (CIO) function that will be a focal point and work with information management leaders to set priorities for Hanford Site information management and orchestrate site information management from a corporate level.

- Improve the review process for new information systems, ensuring appropriate participation by those affected and establishing controls to eliminate redundant efforts.

- Develop compatible information management processes and procedures that meet current needs and are adaptable to future needs.

\section{Success Criteria:}

- A Site CIO function has been established.

- Funding and resources, as described in the business plan, are available to effectively manage information.

- Management is committed and visibly involved in information management.

- Processes, procedures, and Sitewide standards are established, understood, and fully supported, and visibly exhibit to the customer community the ability to grow with changing and expanding customer needs.

- A corporate level perspective of the Hanford Site information management activities is established and maintained.

- Standards are actively used to help facilitate the communication and comparison of data. 
Strategy 2: Sustain Sitewide leadership to ensure effective information management.

Strategy Statement: Leadership is required across the Hanford Site to enable transformation to effective, integrated information management through a closer partnership between. managers, planiners, information providers, information management developers, and customers. This leadership will come from the Site CIO function, but must be based on teaming and communication, and must encompass all programs and functions. This strategy includes the following:

- Refine the information management vision and goals and communicate these to the Hanford Site.

- Ensure senior management concurrence and support for an integrated Sitewide approach to information management.

- Establish a culture where the workforce, while in compliance with information standards and the requirements of the information architecture, retains the freedom to shape and control the specific information management approach as required to meet unique organizational needs.

- Use information management to empower and support all levels of the work force to operate as a team, to continuously learn, to take personal ownership for progress, and to accept change in the workplace.

- Identify key organizational information management decision makers and create a virtual organization based on teaming to implement and manage Sitewide information management business processes.

- Integrate information management into the business planning process for the Site.

\section{Success Criteria:}

- Information management leadership is facilitating active participation by individuals and teams across the Site.

- Management recognizes "value-added" processes for efficient information management.

- Roles and responsibilities are understood and accepted.

- The Hanford Site is recognized as a leader in information management by onsite personnel, the community, and other DOE sites.

- Hanford Site programs and functions willingly share information and have compatible and complementary information management processes. 


\section{Strategy 3: Enhance and refine the data collection process.}

Strategy Statement: Effective data collection processes are essential to ensure that the data are traceable, reliable, accessible, and of appropriate quality for the purpose for which they are generated. Applicable metadata (i.e., data about the data) must be collected with and accompany the data to meet customer requirements, and to ensure the data are adaptable to potential future uses. Cost-effective processes need to be implemented to ensure that data are collected only once and stored and managed as needed to provide for current and future use. The strategy to accomplish this includes the following:

- Implement processes for collecting and protecting data appropriate to the use and requirements for the data.

- Implement controls for ensuring that well-defined objectives and quality criteria are established before data are collected, and guide the data planning and collection process.

- Establish and implement a consistent, integrated approach for defining data quality.

- Require that metadata delineating the pedigree (e.g., source and accuracy of the data, original intended use, definition) be collected, maintained, and made accessible along with the data as appropriate.

- Establish and implement standards for the data collection process to ensure portability, usability, and accessibility of the data.

- Identify appropriate sources and responsibilities for data collection. Manage the data as close to the source as possible.

- Implement electronic data capture, where appropriate and practical, as a means of better documenting and standardizing the capture process and minimizing transcription errors and delivering it in a more timely, cost-effective manner.

\section{Success Criteria:}

- Processes, technologies are used across the Hanford Site to assure that information is reliable, consistent, valid and readily accessible.

- Data are consistently defined, defensible, and of known and appropriate quality, resulting in increased confidence in its use.

- Standard automated processes are in place to achieve efficient collection of data and information.

- Metadata are captured as data are generated and are available to customers along with the data. 
Strategy 4: Develop an information access and delivery mechanism.

Strategy Statement: Information required by both internal and external customers must be easily and quickly accessible from computer workstations. Huge amounts of data and information currently exist in many forms at the Hanford Site. Standard, integrated processes for the management, retrieval, navigation, and timely delivery of data and information must be provided. This strategy includes the following:

- Design and implement automated processes, along with applicable policies, procedures, and standards, for accessing, storing, exchanging, and protecting operational data and information.

- Create quality inventories, with efficient indices and access mechanisms, to facilitate the location of Hanford Site information products.

- Evaluate and establish criteria to determine what historical, current, and future information needs to be preserved. Assemble and index Hanford Site historical and current information on a cost-effective, as-needed basis.

- Provide the required support infrastructure (training, consultation, documentation) to enable customers to understand, access, and use data appropriately to meet their needs.

- Implement the DOE openness initiative by making information easily accessible to both the internal and external customer community, while providing appropriate protection for its integrity.

- For each information system or automated process, determine if the system generates "record material," and incorporate a records capture and retrieval process if applicable.

\section{Success Criteria:}

- Hanford Site customers have electronic access to essential information needed to fulfil their roles.

- Customers are trained to understand the information and to use the delivery mechanism. They are able to easily use and integrate data from multiple programs and projects.

- There is an increased use of information delivery services, with positive feedback from stakeholders that their needs are being met.

- Computer and Operations security protects information, but is not a barrier to legitimate use.

- Mission-critical historical information is available and accessible. 


\section{Strategy 5 Establish information analysis processes that support customer needs.}

Strategy Statement: Use effective information management and information-based analysis processes to support historical and current studies and to provide a baseline of facts for decisionmaking at the Hanford Site. This strategy includes the following:

- Develop a decision based information management system.

- Provide facilitated processes to enable customers to understand and articulate their business needs for information:

- Provide the information technology and information resources so people can use them to provide prompt response to information requests.

- Use information technology to enable open and active communication during decisionmaking and review processes.

- Use information technology to provide an information base to support decisions that can survive future challenges. Provide information management capabilities that allow decision makers to trace their decisions back to the information used in making decisions.

- Provide computer-based tools that facilitate information analysis, visualization, and modeling.

- Provide information management capabilities to support risk management/assessment methodologies.

\section{Success Criteria:}

- Hanford Site performance information is aggregated with other key information, analyzed and translated into actionable information for improvements; trends and correlations are used in reviews, decision making and planning.

- Customer needs for information are accurately and clearly defined and support the business process.

- Easy-to-use, computer-based tools are available and actively used for acquiring access to information and incorporating that information into the analysis process.

- Management and other decision makers rely on accurate, accessible information and information management during the decisionmaking process.

- Decisions are traceable, logical, and defensible because they are information-based.

- New information analysis tools are provided as new analysis requirements are identified. 
Strategy 6: Develop an effective and efficient Hanford Site information architecture.

Strategy Statement: The Hanford Site's information technology designers and implementers require an open and flexible framework, or information architecture, for the development, integration, and upgrading of the Site's information management capabilities. This framework includes the following:

- Define an information architecture that moves the Site toward systems that are fundamentally compatible with each other, supports the integration of information and informed decisionmaking, deals with issues of technical obsolescence and migration, and focuses on meeting current and future Site information management needs.

- Develop a pilot implementation to demonstrate the feasibility and usefulness of the architecture.

- Design, implement, and document the information management capabilities required by the architecture based on experience with the pilot implementation.

- Improve the Site information infrastructure, including the existing network and access to the information superhighway.

- Use technologies and capabilities that are built on evolving computer industry standards and are nonproprietary (to the extent they are reasonable and cost-effective).

- Establish a process that facilitates the continual refinement and updating of Site information management capabilities to meet evolving customer needs.

\section{Success Criteria:}

- The information architecture is used in conjunction with existing information systems to deliver information to the broader Site customer community more efficiently.

- Customers have seamless access to information as architecture based electronic storage and access capabilities are implemented on Sitewide information systems. Reliance on paper versions of information is reduced.

- New systems and capabilities are designed and implemented so they integrate into the architecture's capabilities, are better suited to customer needs, and are brought online more efficiently and cost-effectively while conforming with standards.

- Redundancies and gaps in information management capabilities are reduced.

- There is a clear migration path for existing systems that need to integrate into the information architecture. 


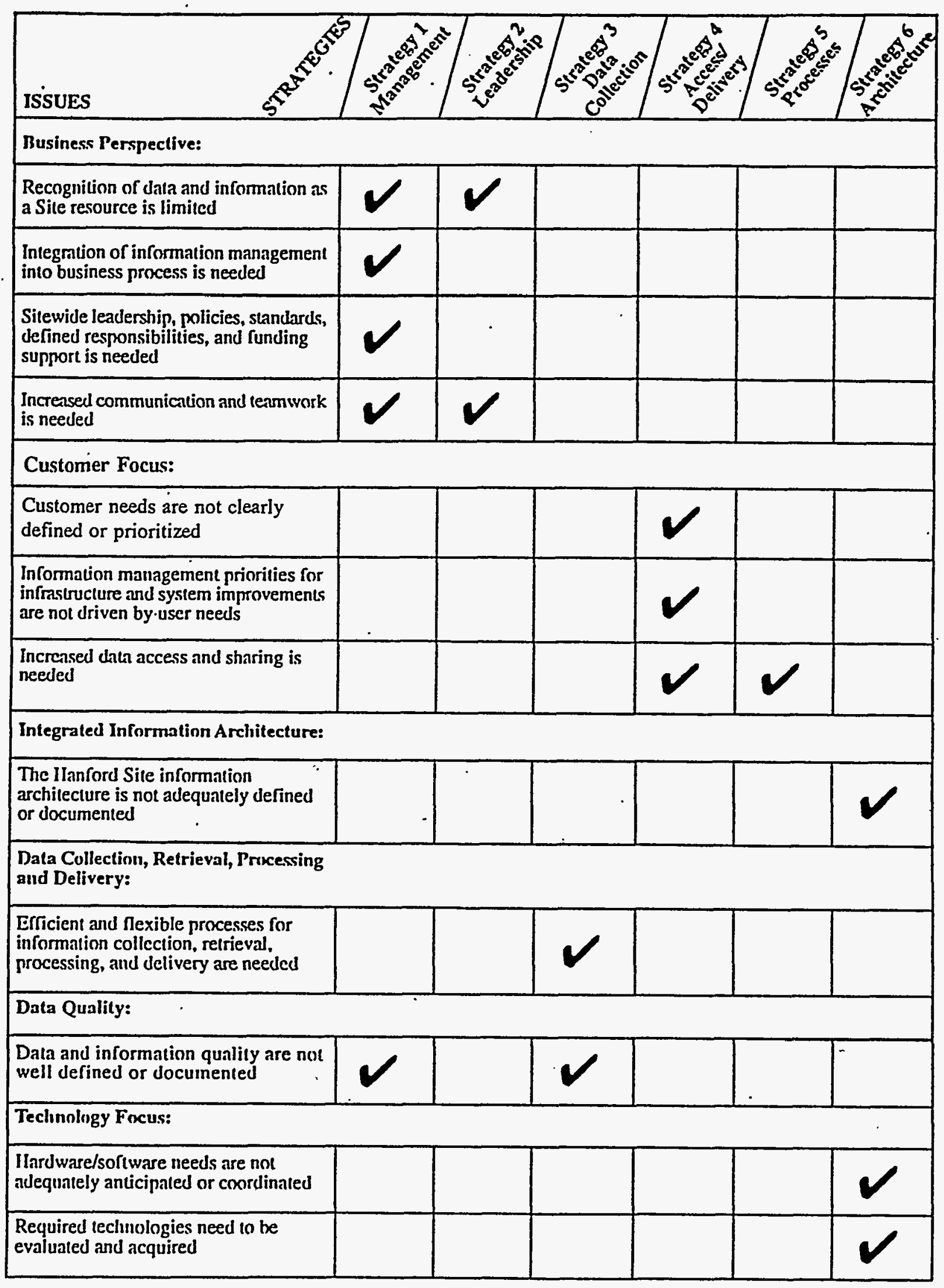

Figure 3. Issues Mapped to Strategies Matrix. 


\subsection{IMPLEMENTING ACTIVITIES}

The formulation of this strategic plan is the first step taken to provide direction for Hanford Site information management. The following business and capability development activities are key to achieving the information management vision. These activities cross-cut the strategies contained in this strategic plan and require the cooperation of all Site organizations. Implementation of these activities is essential to overcome the obstacles and to transform of the Hanford Site's information management culture.

- Develop Data Management Plans (DMP): Data Managements Plans encompassing the Site's key programs and functions will be developed. A data management plan template has been produced as a guideline for developing these plans. The template and additional guidance will facilitate congruency between the documents created by the various programs and functions. This congruency is essential to identify inconsistencies across the programs and functions.

Each DMP will address the detailed questions of resources and timing within its scope. Together the DMPs will support the Site's data and information management needs and identify the current and required information for each program or function including: 'the subject areas, databases, system interfaces, data sources, dissemination, responsibility, location(s), etc. They will address in more detail the activities needed to achieve this plan's strategies and provide tactics for accomplishing its information management goals. Analysis of the DMPs can identify specific program problems that can be corrected easily to offer early results while other problem areas may require long-term actions. Organizations and contractors responsible for the information planning activities for each DMP are as follows: (1) Each DMP will be a chapter in an Integrated Implementation Plan; (2) The development process links the integrated plan and individual DMPs to the fiscal year work plans and the multiyear program plans.

- Provide Leadership: The establishment of a Site CIO function is essential as the authority and focal point for coordination of information and information management resources across the Hanford Site. The coordination of Sitewide information management should include business process organizational and data modeling, which would build on the Systems Engineering process. A responsible organization and business advocate for information management is also needed within each key Hanford Site program and function. The CIO will be responsible for coordinating and prioritizing the Site's short- and long-term information management business investments with the program offices and supporting a balanced approach to meeting Sitewide implementation and infrastructure development needs, including major system acquisition activities. The CIO function will provide a focal point for communicating and sustaining the urgency needed for the capture of and access to new and historical data critical to performing the Site's missions.

A key aspect of this U.S. Department of Energy, Richland Operations Office (RL) and contractor leadership approach is the development and use of a multiprogram staff team supporting the full range of the information management life cycle, including strategic planning, technology acquisition, architecture and systems development, operations, and training. These leaders will work with the Site programs and contractors to stress delivering products and required capabilities.

$\mathrm{RL}$ is currently developing a Strategic Transition Initiatives (STI) Implementation Plan. This plan will identify certain initiatives which involve multiple contractors or site-wide functions. Selected initiatives will use a common approach for planning, understanding, redesigning and 
implementation. Each initiative will be led full-time by a DOE-RL manager, supported as needed by Hanford Site Contractors and outside consultants. The Information Management Transition Initiative, working with Site Information and Program Managers, will develop and implement a Sitewide information management process based on the Strategic Plan for Hanford Site Information Management:

- Sustain Teamwork: Technical and organizational working partnerships between managers, planners, information providers, information system developers, and customers are required across all Site programs. Currently, Hanford Site information management activities are narrowly defined to the individual needs of separate programs and are seldom viewed in relationship to each other.

In addition to Hanford Site customers, many external customers exist including members of the regulatory community, the public, tribal governments, and key interest groups. They are important parts of the customer base and must be included in the information management process.

- Provide Business Focus: The business activities of the Hanford Site programs and functions need well-defined information management responsibilities, accountabilities, processes, and incentives to support their information management needs. Within the context of the information architecture and Sitewide policies and standards, each program or function should develop the data handling and information management capabilities that best serve its individual needs. Currently, the Hanford Site has hundreds of existing systems developed for a variety of purposes, many of which are not scalable, or suitable for use outside the organization that created them. A study to define which systems and system characteristics are truly needed, and a review of how existing systems can serve those purposes must be conducted. Then, new capabilities to fill the gaps can be developed. However, all capabilities must interface to facilitate management of the Site's valuable information resources.

- Acquire Technology: Information management capabilities must be easy-to-use and provide flexible access, search, retrieval, data browsing/navigation, and analysis capabilities for customers. Ongoing evaluation of emerging technology needs to occur. Technology advancement is not optional, it is a prerequisite for meeting evolving customer needs.

- Provide Education and Support: Education plays three roles; first, there is a need to educate the Hanford Site community about the critical role information plays in sustaining and completing the Hanford Site missions; second, individual programs and functions must understand and experience the business benefits of implementing a Sitewide approach to information management as they participate in developing the policy, guidance, and standards; and third, an active training, education, consultation, and support program must be made available for all customers.

Coupled with this plan's strategies, these activities are key to overcoming the obstacles and establishing a new Hanford Site information management culture. The involvement of managers and customers across all Site programs is essential to successful implementation of this plan. The Information Management Transition Initiative team, under the direction of the RL Strategic Transition Initiatives Division, will be responsible for developing the information management business process to enable implementation of the strategies in this plan. The Information and Communications management Team, under-the direction of the RL Site Infrastructure Division, will be responsible for the development and integration of the program and functional data management plans. 


\subsection{REFERENCES}

DOE, 1994, DOE Strategic Plan, DOE/S-0108, U.S. Department of Energy, Washington, D.C.

DOE/HQ், 1994, DOE Information Management Strategic Plan, DOE/HQ-0099, U.S. Department of Energy, Washington, D.C.

DOE/RL, 1994, Strategic Plan for Hanford Site Environmental Restoration Information Management, DOE/RI-94-39, U.S. Department of Energy, Richland Operations Office, Richland, Washington.

DOE/RL, 1994, Tri-Party Agreement Strategic Data Management Plan, DOE/RL-94-111, U.S. Department of Energy, Richland Operations Office, Richland, Washington.

Ecology, EPA, and DOE, 1994, Hanford Federal Facility Agreement and Consent Order, as amended, Washington State Department of Ecology, U.S. Environmental Protection Agency, and U.S. Department of Energy, Olympia, Washington. 


\section{APPENDIX A \\ HANFORD SITE DATA AND INFORMATION MANAGEMENT POLICY}

The Hanford Site recognizes and manages data and information as one of the most important resources in support of its missions and customers. The Site creates an environment that guarantees the right information to the right people, in the right place, at the right time, in the right form, and at the right cost. As good stewards of data and information, the Site information managers adhere to the following policy:

1. Manage data and information from a business perspective. Data and information are maintained and managed based on business needs and objectives. Data architectures are developed to support business processes at functional and company levels.

2. Collect data only once. Data are captured at the origin and entered only once to control data redundancy and consistency. Data sources are identified and managed.

3. Establish and enforce data standards. Data used across Site business activities are identified and defined. Standards are developed so that data can be easily represented and communicated throughout the Hanford Site.

4. Share data based on need. Data are treated as a Site resource and not as the property of a particular individual, organization, or system. Data are made accessible to all authorized customers, contractors, and systems.

5. Control and protect data and information. Data and information are guarded from deliberate, unintentional, or unauthorized alteration, destruction, and/or inappropriate disclosure. Data are controlled throughout their life using established policies and practices.

6. Actively pursue information quality. Data accuracy, availability, accessibility, and usage are established, promoted, and ensured by following specific requirements and criteria. 
This page intentionally left blank. 


\section{APPENDIX B}

\section{THE INFORMATION ARCHITECTURE}

What is an Information Architecture?

The purpose of this appendix is to provide a high-level overview of what is meant by "information architecture." The information architecture is a conceptual framework for information systems implementation and its associated, underlying computer-based infrastructure. The focus of the architecture is to provide the framework for systems integration so customers have the ability to access data anywhere and to run critical applications when and where needed. The architecture will function like a librarian who knows where the resources reside and how to retrieve them.

The architecture facilitates the integration of computer systems that are heterogeneous and distributed. The architecture is not a single computer system, but a set of computer systems that perform different functions and are physically distributed across the Site and off-site. The computer systems are tied together through networks.

\section{Components of the Information Architecture}

There are five major components of the information-architecture: process, data, technology, applications, and organization. These components together form a representation of the "enterprise" (or business) to which the information architecture is related.

1. The process component focuses on what the business does in order to accomplish its work.

2. The data component focuses on what data are needed, generated, updated, and stored. An accepted set of standards is required to provide consistency for data customers.

3. The technology component considers network technology, including installed and planned networks and telecommunications; facilities and their locations; hardware configurations; operational, commercial, and development software; and technical services. This component also describes the policies, strategies, and processing standards for the architecture.

4. The application component provides software capabilities or tools for accessing and using information resources.

5. The organization component is a description of the Hanford Site organizations and their relationships.

When these various components are analyzed together so that the whole enterprise can be understood. 


\section{APPENDIX C}

\section{THE PLANNING PROCESS}

This plan is intended to be a high-level framework for effective information management at the Hanford Site. The motivation for this plan was the Tri-Party Agreement milestone M-35-02 (Ecology, et al., 1991), which calls for a "TPA strategic data management plan." RL decided to increase the scope of that strategic plan to cover the entire Site. The Tri-Party Agreement also calls for the development of data management plans for each RL program (see "Implementing Activities" for further explanation of the Data Management Plans). The data management plans will be the tools utilized to achieve the strategies of this plan. Those plans will be completed by March 1995 and are to be congruent with this plan.

In February 1994, a team, which included regulators and a cross section of staff representing the Hanford Site, was formed and a two-day workshop held. Organizations represented included RL and contractor program offices, RL and contractor information management staff, the Corps of Engineers, the U.S. Environmental Protection Agency, and the Washington State Department of Ecology. The team defined the vision, values, and goals for improved information management. A situational analysis was conducted, which included examining trends, assumptions, strengths, weaknesses, and obstacles, identifying opportunities, and developing strategies for improvement. The result of that workshop was a skeleton of this strategic plan, which was refined in a four-hour followup workshop held in March 1994. A writing team used that skeleton plan as well as other relevant plans to create this strategic plan. A list of team members and others who participated in the development or review of this plan follows.

Westinghouse Hanford Company

R. L. Aikens

M. K. Britton

F. T. Calapristi

D. B. Cartmell

S. J. Dechter

R. D. Fox

K. K. Friday

K. K. Giamberardini

D. L. Greenslade

T. G. Halverson

H. H. Heacock

M. L. Heinemeyer

K. L. Hladek

W. A. Hollenbeck

J. T. Knight

E. J. Kosiancic

T. M. Lutter

F. M. Mann

\section{Westinghouse Hanford Company (cont.)}

D. A. Marsh

S. B. McCargar

J. V. Nelson, Jr.

J. A. Nielsen-

S. M. O'Toole

J. M. Pinkerton

S. B. Roakes

J. B. Schaffer

D. J. Sommer

D. R. Speer

R. J. Uhlrich

R. K. Welty

W. G. Wilson

G. M. Wise

H. H. Yoshikawa

M. F. Zakrajsek 
U.S. Department of Energy,

Richland Operations Office

J. M. Augustenborg

S. E. Bullard

T. D. Cress

Boeing Computer Services, Richland

A. D. Ballinger

S. I. Bennion

D. R. Brandes

S. L. Burns

S. R. Kelley

M. J. Koons

M. M. Ledgerwood

J. R. Lewis

G. C. Main

B. J. Miller

J. R. Phillips

B. L. Preecs

R. N. Richardson

L. S. Teller

C. F. Wagner

\section{Pacific Northwest Laboratories}

J. E. Beck

J. C. Brown

N. G. Carter

P. J. Cowley

R. E. Gephart

L. A. Holmes

J. S. Littlefield

R. E. Mahan

R. C. McVeety

S. J. Ortiz

J. M. Paananen

K. M. Probasco

P. K. Schuette
Washington State Department of Ecology

J. W. Yokel

U.S. Environmental Protection Agency

D. R. Einan

\section{U.S. Army Corps of Engineering}

M. P. Blancq

Hanford Environmental Health Foundation

B. J. Caldwell

J. J. Maher

ICF Kaiser Hanford Company

A. H. Friberg

MAC Technical Services Company

J. J. Pagel

T. Powell

P. J. Walker

$\underline{\text { MCE Technical Services }}$

E. H. Schubert 


\section{APPENDIX D}

\section{PLANNING DOCUMENT HIERARCHY}

The illustration of the planning document hierarchy (Figure 4) shows the relationship of this plan to some other planning efforts underway at the Site and the U.S. Department of Energy (DOE) complex.

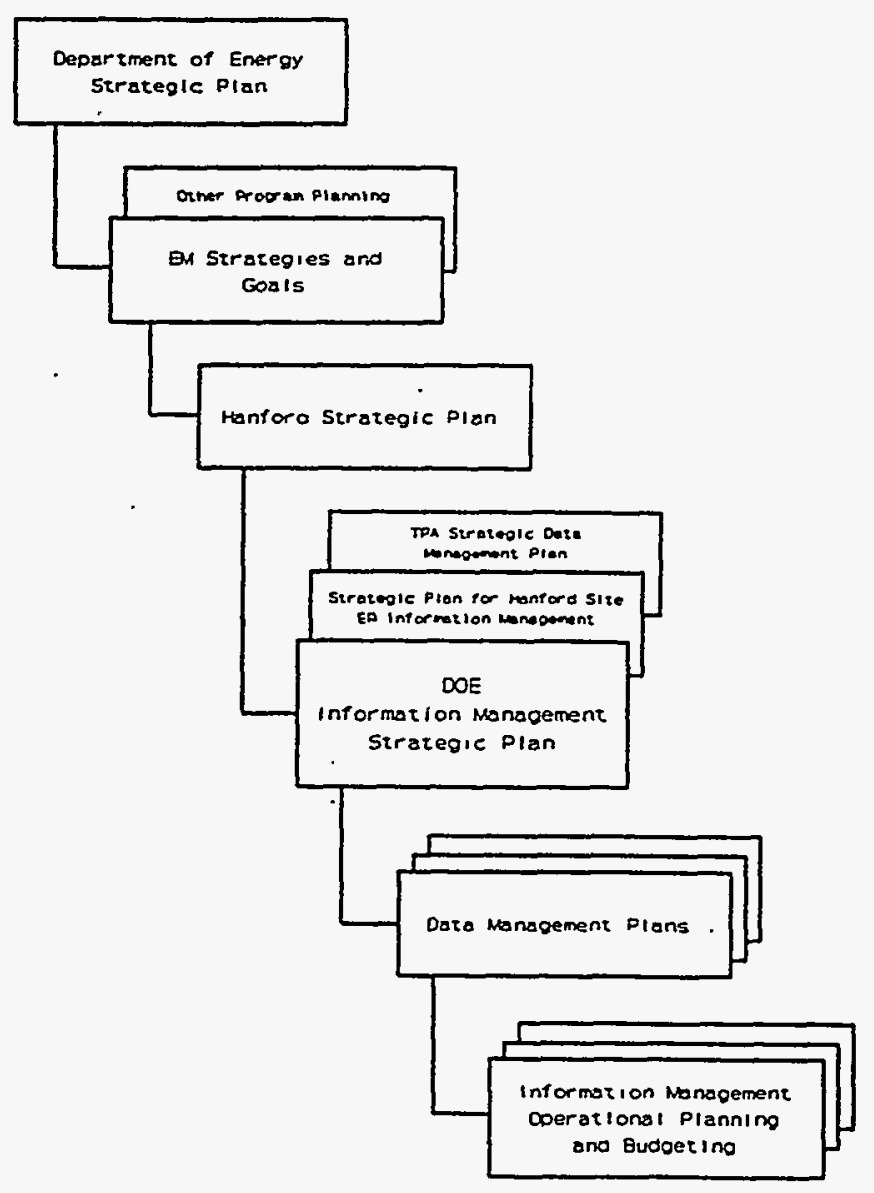

Figure 4.

The top level document is the DOE Strategic Plan, released April 1994 (DOE 1994). This plan realigns and integrates the department's unique scientific and technological assets to achieve the vision of moving away from the cold war economy; investing in people and technology to strengthen the economy and protect the environment; and reinventing a government that is efficient, serves the American people, and provides more services with fewer resources.

The Environmental Management (EM) Strategies and Goals aligns with the vision of the DOE Strategic Plan to achieve the vision of DOE EM, serving as a model for public management of environmental protection activities driven by a combination of customer expectations, and technical and 
scientific capabilities. Other documents addressing specific programmatic areas are anticipated to serve a similar vision applicable to their function.

The Hanford Strategic Plan (HSP) addresses all Hanford Site activities and the commitment by DOE, while completing the mission of environmental cleanup and meeting global needs, to partner in the economic diversification of the region. The HSP is being aligned with the DOE Strategic Plan. In its current draft form, the HSP cites the following, all of which have information management components: the need.for timely, quality information; improving the decisionmaking process; providing a more open and accessible communication system that promptly responds to public information requests and reaches out to the public and media to share information; and improving the quality of risk assessment information to understand the real hazards faced by workers, the public and the environment.

The Strategic Plan for Hanford Site Information Management focuses on information management activities and works to achieve alignment, where possible, with other documents of the hierarchy. The Strategic Plan for Hanford Site Environmental Restoration Information Management (DOE/RL 1994) shares many similarities with the Strategic Plan for Hanford Site Information Management, but addresses the specific needs of the ER program. The Tri Party Agreement Strategic Data Management Plan addresses the specific needs of the regulator community and Hanford Site programs involved in the Site cleanup mission.

The DOE Information Management Strategic Plan, released July 1994, describes the Department's information management strategy and identifies implementing activities to accomplish the Department's information management goals.

The Data Management Plans, described in further detail in the Implementing Activities section of this plan, will address the detailed questions of current and needed information and processes for each program or function at the Hanford Site. Tactical information from the WHC Strategic Information Plan will be incorporated into the Data Management Plans. These plans will be available in March 1995.

The Information Management Operation Planning and Budgeting block in the hierarchy indicates that the Hanford Site will utilize the goals and objectives described in strategic plans to prepare multiyear program plans, operational plans, and budgets within each program office. 